\title{
Protein Profile of Human Saliva as a Predictive and Prognostic Tool for OSCC in Tamol Chewer's Population in Assam
}

\author{
Lhakit lepcha $^{1 *}$, Manash P Sarma², Amal C Kataki³, Wankupar Wankhar, \\ B G Unni ${ }^{2}$
}

\begin{abstract}
Objective: To identify potential proteomic salivary biomarker in tamol chewers and comparing it to healthy and Oral squamous cell carcinoma cases. Methods: A total of fifty unstimulated saliva samples were collected from the healthy volunteers, tamol chewers (without tobacco), and OSCC patients referred to North-East cancer Hospital, Jorabat, Assam, India. The 2-D gel analysis and western blotting were performed to analyze protein profiling. Results: The identified proteins were serum albumin, HSP (Heat shock protein) 27, gamma actin, SCC (Squamous cell carcinoma) 1, and Annexin A4. All the proteins were associated with OSCC development when their values were compared with those of normal healthy subjects. HSP27 was subjected to further validation using western blotting methods. An increase of 18.39\% (Serum Albumin), 15.04\% (gamma actin), 14.01\% (SSC 1), and 20.22\% (ANX4) were observed in Tamol chewers when compared with healthy control subjects. Conclusion: Our results revealed that the identified salivary proteins have a positive association with OSCC development. Profiling of these saliva proteomes especially HSP (Heat shock protein) 27 as a potential biomarker for OSCC detection in the high-risk population is recommended.
\end{abstract}

Keywords: OSCC- Oral squamous cell carcinoma- ANXA4 - Annexin A4- HSP-Heat shock protein- SCC

Asian Pac J Cancer Prev, 22 (6), 1837-1841

\section{Introduction}

Oral cancer, histologically about $90 \%$ in the form of oral squamous cell carcinoma (OSCC), is a high-effect and common form of disease-related with the oral cavity (Gupta et al., 2013; Mascitti et al., 2018). Many environmental and genetic factors are often associated with the development of this disorder but the major regional predisposing risk factor for OSCC is chewing of betel quid and "paan" in India (Garg et al., 2014; Lepcha et al., 2021). World Health Organization and International Agency for cancer research classified areca nut as a group-I human carcinogen with enough verification of increased risk of precancerous oral lesion and cancer of the oral cavity (Hernandez et al., 2017). In Northeast India, a variety of raw areca nut is used in combination lime paste and piece of betel leaf without tobacco locally termed as tamol in Assam. Frequent and regular scratches of betel nut and betel leaf form ulcers in the oral cavity (Kumar et al., 2021). Comprises strong chemical compound in slaked lime which further forms scars or ulcers by burns the soft tissue in the oral cavity. Which can further be a main contributing factor for developing oral cancer (Phukan et al., 2001; Borkotoky et al., 2020).

OSCC diagnosis depends on a thorough oral cavity examination, for possible signs and symptoms of the disease, followed by tissue biopsy. Besides diagnosis based on tissue, and body fluids like saliva and blood are the extensively studied samples that may comprise consistent biomarkers for cancer analysis. The saliva sample is an enlightening body fluid containing a range of analytes such as protein (Singh et al.,2020; Roi et al., 2020), mRNA (Oh et al., 2020), antioxidant profile (Lepcha et al., 2019), and DNA (Lepcha et al., 2021; Borkotoky et al., 2020) which can be used as diagnostic and prognostic markers for clinical and therapeutic applications. Several studies have investigated the use of salivary proteins as a potential diagnostic marker for oral cancer. The identification of proteins is either cleaved by gel electrophoresis or enzymatic digestion by the procedure to produce peptides (Hu et al., 2008; Ploypetch et al., 2020). Approximately, 3000 proteins have been identified in saliva by using various procedures (Hu et al., 2008; Jarai et al., 2012; Ploypetch et al., 2020). Similarly, various potential biomarkers identified from the saliva of OSCC such as cytokeratin 19 fragment (Cyfra21-1) (Rathore et al., 2020), albumin (Nguyen et al., 2020), telomerase (Sannam et al., 2016), transferrin (Nguyen et al., 2020), glutathione (Singh et al., 2020) were identified.

Thus, analyzing salivary protein profiles as potential biomarkers or molecular targets for early detection for OSCCs in tamol chewers and a feasible target to screen 
the population.

\section{Materials and Methods}

Methods

Sample preparation

50 unstimulated saliva samples were collected from two groups of individuals i.e., raw betel nut chewers (non-alcohol and tobacco individuals), and control sample (non-raw betel nut, alcohol, and tobacco consumers) from Garo Goun, Mayang village, Panikhaiti area, and North-East cancer Hospital, Assam. Both males and females above 15 years were taken into consideration. All methods were performed in accordance with the relevant guidelines and regulations of the Ethics Committee of Dr. Bhubaneswar Borooah Cancer Institute, Assam, India (Registration no. BBCI/Misc-119/MEC/1065/2016). Protein was isolated by using Trizol solution and concentration of salivary protein was measured using the Bradford methods for tamol chewers and healthy individuals.

\section{2-D electrophoresis}

Protein from tamol chewers and healthy individuals was dissolved in $125 \mu \mathrm{L}$ of strip reswelling solution, soaked for a night at room temperature. And run in IEF unit, after isoelectric focussing strips were transferred into tray and covered with the reduction solution and incubate for $10 \mathrm{~min}$. After 10 minutes, the reduction solution was removed and strips were covered with alkylation solution incubate for 10 mins. After 10 minutes alkylation solution was aspirated using Pipette and rinsed with tris glycine buffer. Strip was placed in SDS-PAGE gel (12\%) above the resolving front and was overlayer with agarose heated at $70^{\circ} \mathrm{C}$. the gels were stained with silver nitrate solution. The image was captured in gel documentation equipped with Canon EOS1300D.

\section{Western Blotting}

Western blotting was performed according to Towbin et al., (1984) Saliva samples were prepared with radioimmunoassay buffer (RIPA) (Sigma) and a protease inhibitor. Equal amounts of protein $(30 \mu \mathrm{g})$ were electrophoresis on $12 \%$ SDS-PAGE. Following electrophoresis, separated proteins on SDS-PAGE gels were transferred onto the PVDF membrane (Millipore, USA). To block the nonspecific binding, membranes were incubated in blocking buffer with 5\% skimmed milk for $2 \mathrm{~h}$. Membranes were probed with primary antibodies (1:600) and blots were incubated with horseradish peroxidase-conjugated secondary antibodies $(1: 1,000)$. The bands were developed using an ECL kit (Millipore, USA) in the Chemi Doc image scanner from Bio-Rad. To estimate/quantify the band intensity, Quantity One software (Bio-Rad, USA) is used. The membranes were stripped and re-probed for $\beta$-actin (Sigma) (1:500) as an internal control.

\section{Results}

$2 \mathrm{D}$ gel analysis of saliva sample in OSCC

The demographic features and socio-economic position of the studied population are taken on a standard performa. In tamol chewers $23.6 \%$ of the studied population were male and $76.4 \%$ female respectively. Similarly, in the control sample $69 \%$ were male and $31 \%$ female. Higher proportions of females (76.4\%) were found in the tamol chewer categories since the maximum male population was also involved in tobacco and alcohol consumption. No substantial difference was observed in both the categories concerning age, BMI, education, and profession.

The mean and SD of total protein of the control sample and tamol chewers were $1531.3 \pm 256.1$ and $4829.2 \pm 2656.8$ respectively. Proteins used for the 2-DE were evenly distributed in the $7 \mathrm{~cm}$ gel with $\mathrm{pH}$ the range from 3-10 and with molecular masses of $5-245 \mathrm{kDa}$. Protein spots were detected in each gel by the Image Master software in Figure 1, which shows typical gel images for both normal control and tamol chewers population. 5 differentially expressed proteins had been identified and are upregulated or when compared with normal healthy individuals' samples. Serum albumin,

Table 1. List of Identified Proteins Found Upregulated in Tamol Chewers as Compared with Healthy Individuals

\begin{tabular}{|c|c|c|c|c|}
\hline Spot number & Molecular weight (kDa) & Fold change & Protein name & Reference \\
\hline 318 & 67 & 2.9 & Serum albumin & $\begin{array}{l}\text { Koduru et al.,2017 } \\
\text { Meurman et al.,2002 }\end{array}$ \\
\hline 266 & 27 & 5.9 & Heat shock protein 27 & $\begin{array}{l}\text { Lu et al.,2021 } \\
\text { Wan et al., } 2009 \\
\text { Zhu et al., } 2010 \\
\text { Suzuki et al., } 2007 \\
\text { Fan et al., } 2020\end{array}$ \\
\hline 257 & 41 & 3.8 & Gamma Actin & $\begin{array}{l}\text { Sannam et al., } 2016 \\
\text { Duncan et al.,2008 } \\
\text { Roman et al.,2013 }\end{array}$ \\
\hline 196 & 45 & 5.2 & $\begin{array}{c}\text { Squamous cell carcinoma } \\
1\end{array}$ & $\begin{array}{l}\text { Roman et al.,2013 } \\
\text { Krapfenbauer et al.,2014 } \\
\text { Nikitakis et al., } 2003\end{array}$ \\
\hline 204 & 34 & 3.8 & ANXA4 & $\begin{array}{l}\text { Zimmermann et al., } 2004 \\
\text { Gerke et al.,2005 } \\
\text { Kim et al., } 2010 \\
\text { Liu et al.,2016 }\end{array}$ \\
\hline
\end{tabular}



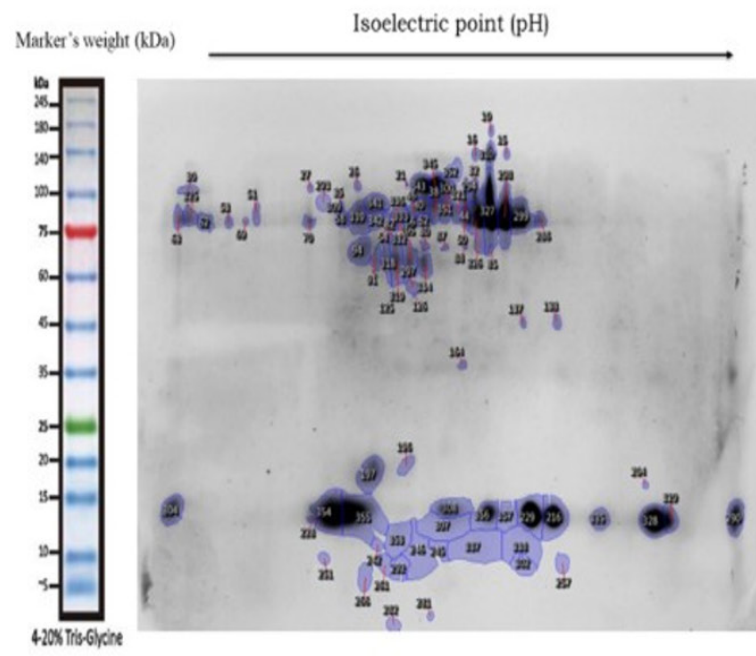

A

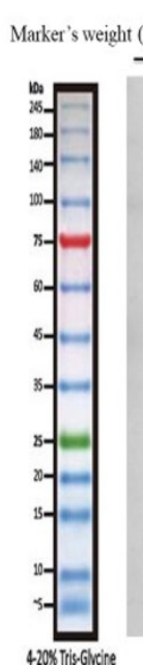

4206 TisisGohicre
Isoelectric point $(\mathrm{pH})$

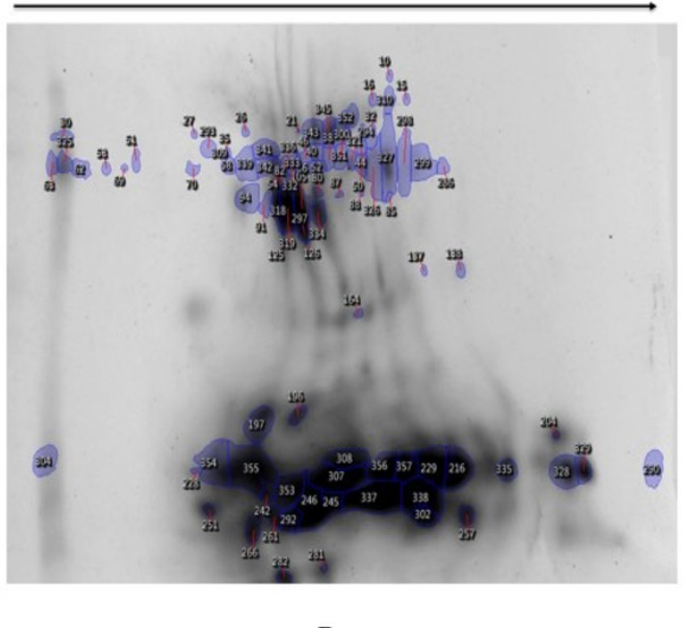

B

Figure 1. Image of 2D Gel Representing. A, Normal control; B, Tamol chewers sample

Heat shock protein 27 (HSP 27), gamma actin, squamous cell carcinoma (SCC) 1, and Annexin A4 (ANXA4) were identified proteins and have a positive association with OSCC development (Figures 1, 2 and Table 1).

\section{Protein expression of HSP27}

To understand the involvement of HSP27 protein, one control, one cancer sample, and four tamol chewers (TC) were run using western blotting technique. Band intensities in tamol chewers OSCC were all significantly higher with a consecutively upregulated trend from control and OSCC patient's sample respectively. An increase of $18.39 \%, 15.04 \%, 14.01 \%$, and $20.22 \%$ was observed in TC1, TC2, TC3, and TC4 when compared with the control sample respectively. Representative results were presented in Figure 3.

\section{Discussion}

Five different proteins identified were serum albumin, Heat shock protein 27, gamma actin, squamous cell carcinoma 1 (SCCA-1), and ANXA4 when compared to the control sample. These identified proteins have often shown a positive association with OSCC development either upregulated or . Family of actin are associated with cell mortality, junction organization, axon guidance, and also play important role in tumorigenesis. The presence of gamma actin in saliva can contribute especially to cancer diagnosis and prognosis (Sannam et al., 2016; Duncan et al., 2008; Roman et al., 2013). SCCA-1 another protein identified serves as an important tool for diagnosis and treatment marker for OSCC patients (Krapfenbauer et al., 2014). SCCA-1 were found in tamol chewers then normal healthy case which indicates the positive association of tamol consumption with the development of OSCC. Similar results were reported as SCCA-1 as an important immunohistochemical marker in different cancer stages (Nikitakis et al., 2003). Upregulated SCCA-1 found in clinical patients with tongue cancer has been suggested as a potential biomarker not only for the tongue but also for Head and neck cancer (Roman et al., 2013).

Among all the annexins, ANXA4 is associated with cell adhesion, apoptosis, carcinogenesis, and invasion
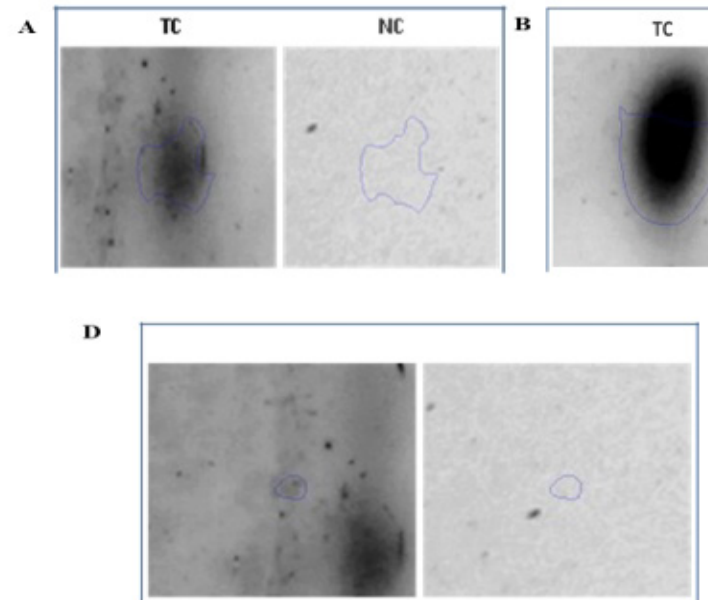

$\mathbf{E}$

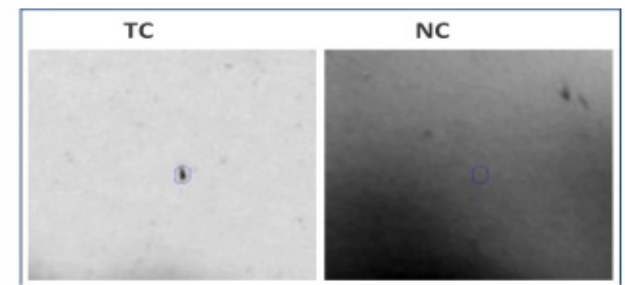

Figure 2. Five Upregulated Protein in Tamol Chewers as Compared with Normal Control. A, Serum albumin; B, Heat shock protein 1; C, Gamma actin; D, squamous cell carcinoma 1; E, ANXA4 while referring with their molecular weight $(\mathrm{kDa})$ 

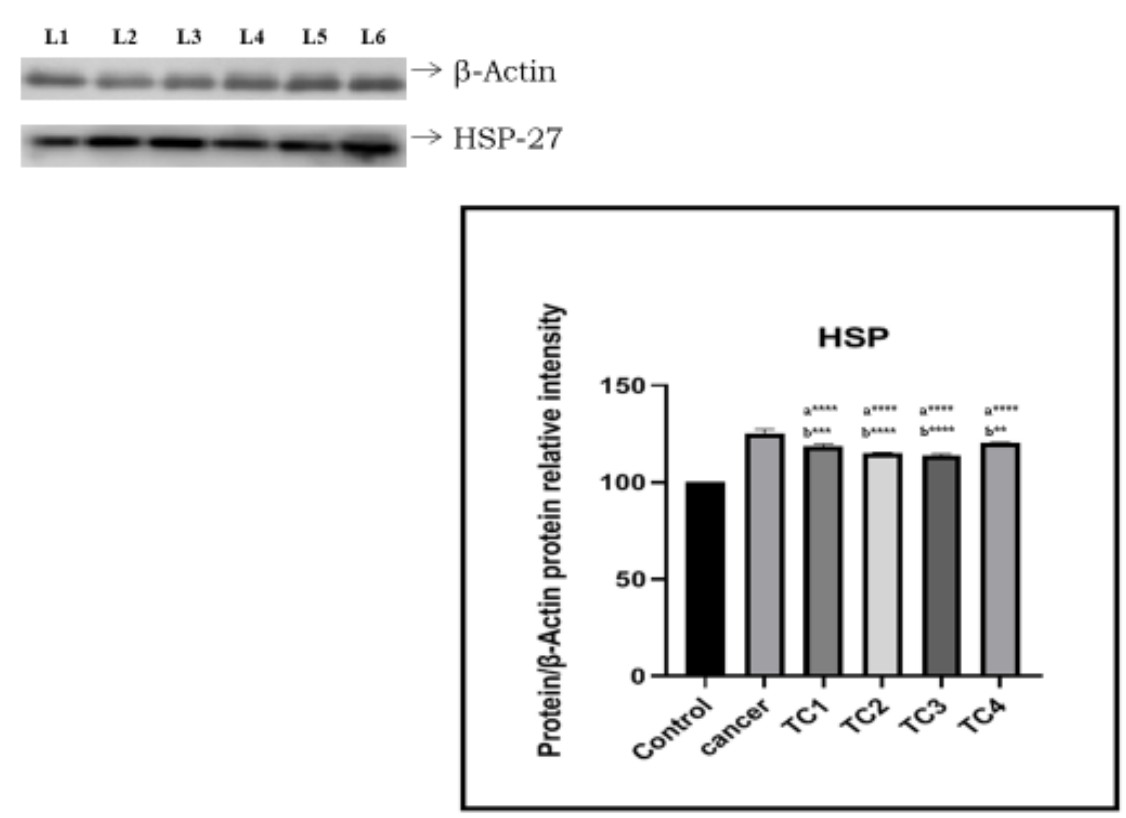

Figure 3. Protein Expression of HSP-27. L1: Con; L2: Cancer sample; L3: TC1 (Tamol chewers 1) - 1; L4: TC2 (Tamol chewers 2); L5: TC3 (Tamol chewers 3); L6: TC4 (Tamol chewers 4). Data are expressed as Mean \pm SD. "a"compared to control. "b" - Compared to Tamol chewers. The significance level was fixed at "*” $p<0.05$; "**" $p<0.01$; "***" $\mathrm{p}<0.001$ and “****" $\mathrm{p}<0.0001$

of cancer cells (Zimmermann et al., 2004). ANXA4 was found in various other complications such as renal (Zimmermann et al., 2004), gastric cancer (Gerke et al., 2005), ovary cancer (Kim et al., 2010), and buccal squamous cell carcinoma (Liu et al., 2016). proteinenhanced significantly with tumor stage led to poor prognosis and associated with metastasis (Gerke et al.,2005; Kim et al., 2010). Koduru et al., (2017) reported a significant increase of salivary albumin in oral cancer cases as compared with healthy individuals and chronic genperiodonities. The increased salivary albumin level in oral pre-malignant and oral malignancy cases compared with healthy individuals served as an early diagnosis and prognostic role for oral malignant cases (Meurman et al., 2002). On the other hand, HPSs, also known as stress protein is expressed in a wide variety of physiological and environmental stress. Mammalian HSPs are classified into 5 categories according to their molecular weight $(\mathrm{Lu}$ et al., 2021). The ATP-dependent chaperone families HSP70 and HSP27 are the most studied protein because of their involvement in oral cancer (Lu et al., 2021) and are frequently related to the progression of tongue squamous cell carcinoma and also serve as an important biomarker (Wan et al., 2009). Our result has also identified the presence of HSP27 in oral squamous cell carcinoma in tamol chewers.

To confirm the involvement of HSP27, western blotting technique was carried out. HSP27 expression was significantly higher in tamol chewers as compared with the control sample. An increase of $18.39 \%, 15.04 \%$, $14.01 \%$, and $20.22 \%$ was observed in TC1, TC2, TC3, and TC4 when compared with the control sample respectively. This supports the role of HSP27 in the development of oral cancer among tamol chewers population and potential salivary biomarker in oral squamous cell carcinoma. A similar result was stated by using proteomic technologies, among 85 different altered protein in OSCC, HSP27 was found upregulated in different histological grade of the premalignant lesion and OSCC (Wan et al., 2009; Zhu et al., 2010; Suzuki et al., 2007; Fan et al., 2020).

In conclusion, our results reveal that profiling of saliva proteome can be a feasible marker to screen the population with the highest risk and also identify HSP27 as a potential salivary marker for OSCC detection.

\section{Credit authorship contribution statement}

Lhakit Lepcha: Conceptualization, Methodology, Validation, Investigation, Investigation, Writing - original draft. Manash P Sarma: Conceptualization, Writing review \& editing. Amal C Kataki: Writing - review \& resources. Wankupar Wankhar: Investigation, resources. BG Unni: Resources.

\section{Author Contribution Statement}

None.

\section{Acknowledgments}

The author acknowledges the financial support received from Assam Downtown University in the form of a seed grant and Dr. Bhubaneswar Borooah Cancer Institute and North East Cancer Hospital and Research Institute for providing research samples and technical help for undertaking the research work.

\section{Conflicts of interest}

There are no conflicts of interest. 


\section{References}

Borkotoky R, Malakar B, Saikia AK, Mukherjee SN, Bose S (2020). Alterations in XRCC1 gene profile in pathogenesis of oral cavity cancer: A population-based study from Kamrup Urban District of Assam, India. Curr Probl Cancer, 44, 100473.

Duncan R, Carpenter B, Main LC, Telfer C, Murray GI (2008). Characterisation and protein expression profiling of annexins in colorectal cancer. Br J Cancer, 98, 426-33.

Fan G, Tu Y, Wu N, Xiao H (2020). The expression profiles and prognostic values of HSPs family members in Head and neck cancer. Cancer Cell Int, 20, 1-12.

Garg A, Chaturvedi P, Gupta PC (2 014). A review of the systemic adverse effects of areca nut or betel nut. Indian journal of medical and paediatric oncology: official journal of Indian Society of Medical \& Paediatric Oncology, 35, 3.

Gerke V, Creutz CE, Moss SE (2005). Annexins: linking Ca $2+$ signalling to membrane dynamics. Nat Rev Mol Cell Biol, 6, 449-61

Gonçalves LDR, Soares MR, Nogueira FCS, et al (2011). Analysis of the salivary proteome in gingivitis patients. J Periodontal Res, 46, 599-606.

Gupta B, Ariyawardana A, Johnson NW (2013). Oral cancer in India continues in epidemic proportions: evidence base and policy initiatives. Int Dent $J, \mathbf{6 3}, 12-25$.

Hernandez BY, Zhu X, Goodman MT, et al (2017). Betel nut chewing, oral premalignant lesions, and the oral microbiome. PLoS One, 12, e0172196.

$\mathrm{Hu} \mathrm{S}$, Arellano M, Boontheung P, et al (2008). Salivary proteomics for oral cancer biomarker discovery. Clin Cancer Res, 14, 6246-52.

Jarai T, Maasz G, Burian A, et al (2012). Mass spectrometrybased salivary proteomics for the discovery of head and neck squamous cell carcinoma. Pathol Oncol Res, 18, 623-8.

Kim A, Serada S, Enomoto T, Naka T (2010). Targeting annexin A4 to counteract chemoresistance in clear cell carcinoma of the ovary. Exp Opinion Ther Targets, 14, 963-71.

Koduru MR, Ramesh A, Adapa S, Shetty J (2017). Salivary albumin as a biomarker for oral squamous cell carcinoma and chronic periodontitis. Ann Med Health Sci Res, 2017.

Krapfenbauer K, Drucker E, Thurnher D (2014). Identification of tumour-related proteins as potential screening markers by proteome analysis - protein profiles of human saliva as a predictive and prognostic tool. EPMA J, 5, 1-15.

Kumar A, Oswal K, Singh R, et al (2021). Assessment of areca nut use, practice and dependency among people in Guwahati, Assam: a cross-sectional study. Ecancermedicalscience, 15.

Lepcha L, Sarma MP, Kataki AC, Unni BG (2019). Clinical significance of antioxidant levels in saliva of raw betel nut chewer's: an Experience from Assam. Cancer, 3, 5.

Lepcha L, Sarma MP, Kataki AC, Unni BG (2021). Association of X-ray repair cross-complementing group $1 \mathrm{Arg} 399 \mathrm{gln}$ polymorphisms with the susceptibility to develop oral squamous cell carcinoma in tamol chewer's population in Assam, India. Indian J Dent Sci, 13, 73.

Liu W, Zeng L, Li N, et al (2016). Quantitative proteomic analysis for novel biomarkers of buccal squamous cell carcinoma arising in background of oral submucous fibrosis. BMC Cancer, 16, 1-11.

Lu W, Wang Y, Gan M, Duan Q (2021). Prognosis and predictive value of heat-shock proteins expression in oral cancer: A PRISMA-compliant meta-analysis. Medicine, 100. https:// dx.doi.org/10.1097\%2FMD.0000000000024274

Mascitti M, Orsini G, Tosco V, et al (2018). An overview on current non-invasive diagnostic devices in oral oncology. Front Physiol, 9, 1510.
Meurman JH, Rantonen P, Pajukoski H, Sulkava R (2002). Salivary albumin and other constituents and their relation to oral and general health in the elderly. Oral Surg Oral Med Oral Pathol Oral Radiol Endodontol, 94, 432-8.

Nguyen TTH, Sodnom-Ish B, Choi SW, et al (2020). Salivary biomarkers in oral squamous cell carcinoma. J Korean Assoc Oral Maxillofacial Surg, 46, 301.

Nikitakis NG, Rivera H, Lopes MA, et al (2003). Immunohistochemical expression of angiogenesis-related markers in oral squamous cell carcinomas with multiple metastatic lymph nodes. Am J Clin Pathol, 119, 574-86.

Oh SY, Kang SM, Kang SH,et al (2020). Potential salivary mRNA biomarkers for early detection of oral cancer. J Clin Med, 9, 243.

Phukan RK, Ali MS, Chetia CK, Mahanta J (2001). Betel nut and tobacco chewing; potential risk factors of cancer of oesophagus in Assam, India. Br J Cancer, 85, 661-7.

Ploypetch S, Roytrakul S, Phaonakrop N, et al (2020). In-gel digestion coupled with mass spectrometry (GeLC-MS/MS)based salivary proteomic profiling of canine oral tumors. $B M C$ Veterinary Res, 16, 1-17.

Rathore AS, Katyal S, Jain A, Shetty D C (2020). Biochemical analysis of cytokeratin fragment 21-1 concentration and expression of cytokeratin 19 in oral potentially malignant disorders. J Cancer Res Ther, 16, 452.

Roi A, Roi CI, Negruțiu ML, et al (2020). The challenges of OSCC diagnosis: Salivary Cytokines as potential biomarkers. J Clin Med, 9, 2866.

Roman E, Lunde MLS, Miron T, et al (2013). Analysis of protein expression profile of oral squamous cell carcinoma by MALDI-TOF-MS. Anticancer Res, 33, 837-45.

Sannam Khan R, Khurshid Z, Akhbar S, Faraz Moin S (2016). Advances of salivary proteomics in oral squamous cell carcinoma (OSCC) detection: an update. Proteomes, 4, 41.

Singh P, Verma JK, Singh JK (2020). Validation of salivary markers, IL-1 $\beta$, IL-8 and Lgals3bp for detection of oral squamous cell carcinoma in an Indian population. Sci Rep, 10, $1-9$.

Suzuki H, Sugimura H, Hashimoto K (2007). Overexpression of heat shock protein 27 is associated with good prognosis in the patient with oral squamous cell carcinoma. Br J Oral Maxillofacial Surg, 45, 123-9.

Towbin H, Gordon J (1984). Immunoblotting and dot immunobinding-current status and outlook. J Immunological Methods, 72, 313-40.

Wang A, Liu X, Sheng S, et al (2009). Dysregulation of heat shock protein 27 expression in oral tongue squamous cell carcinoma. BMC Cancer, 9, 1-8.

Zhu Z, Xu X, Yu Y, et al (2010). Silencing heat shock protein 27 decreases metastatic behavior of human head and neck squamous cell cancer cells in vitro. Mol Pharm, 7, 1283-90.

Zimmermann U, Balabanov S, Giebel J, et al (2004). Increased expression and altered location of annexin IV in renal clear cell carcinoma: a possible role in tumour dissemination. Cancer Lett, 209, 111-8.

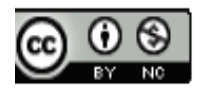

This work is licensed under a Creative Commons AttributionNon Commercial 4.0 International License. 